\title{
QUALITY OF LIFE COMPARISON OF PEOPLE WITH AND WITHOUT DIABETES MELLITUS
}

Eva Živčicová ${ }^{1}$, Monika Gullerová ${ }^{2}$

\begin{abstract}
Quality of life is distinctly conceived as a construct, and, therefore, is distinctly defined and measured. The main purpose of this article was to compare the quality of life assessment in respondents with and without diabetes mellitus by using World Health Organization Quality of Life Assessment (WHOQOL-BREF) questionnaire. Then, quality of life in several major domains, such as physical health, psychological domain, social relationships, and environment is assessed and compared. Finally, a quality of life profile in respondents with and without diabetes mellitus in the Czech and Slovak Republic is produced and compared.
\end{abstract}

JEL Classification Numbers: I19, DOI: http://dx.doi.org/10.12955/cbup.v3.609

UDC Classification: 159.9

Keywords: quality of life, quality of life measurement, domains of quality of life, subjective quality of life assessment

\section{Introduction}

Rapley (2003) suggests that quality of life (QoL) reflects the social dimension of life - standard of living or the so called "state of states" according to sociologists and political scientists, whereas the same notion refers to life satisfaction or the state of the person according to psychologists and doctors. Lane (1996) understands high quality of life in terms of subjective well-being, human development, and justice. The World Health Organization (WHO) defines quality of life as "individuals' perception of their position in life in the context of the culture and value systems in which they live and in relation to their goals and expectations" (WHOQOL-Group, 1998, p. 551). Some psychologists, however, argue that the WHO definition lacks a significant component of quality of life, namely a value - the ancient concept of a good life. Having supplemented the definition with values, the definition of quality of life by Kováč (2006, p. 20) refers to "how an individual perceives and assesses his or her life, and whether he or she lives in harmony or conflict with the community and the culture he or she is a part of." The most common approach to defining life quality includes studying its partial components. Currently, the study of domains (components) includes the subjective dimension, i.e. the extent of subjective satisfaction with objective determinants of quality of life. Under this approach, Pullman, Kompiš, \& Bochníčková (2007) delineate quality of life as "the set of quality indicators that give humans the ability to accomplish their mission in the various stages of life." On the other hand, a holistic approach attempts to examine the structure of quality of life and its subjective meaning with a phenomenological emphasis. Both approaches, however, are based on the characteristics of quality of life as a multidimensional construct encompassing economic, social, and psychological dimensions. We acknowledge that over the period of life, some of those aspects may become dominant, while others may be suppressed. Tokárová (2002, p. 26) views quality of life as "the complex category embracing social, biological, psychological conditions of life." The World Health Organization (WHO) also says that quality of life is a multidimensional construct encompassing both objective conditions and subjective well-being. Several authors focus on the health-related quality of life. Moreover, the terms "quality of life" and "health-related quality of life" are used interchangeably in some contexts by Pacione (2003). Hancock (2000), however, maintains that health requires more than medical care. It needs a supportive network of family, friends, and neighbors; a clean and safe environment; good living conditions and safe and satisfying work; healthy personal behaviors, and a sense of meaning, purpose, even spirituality. As a result, high quality of life is achieved. Regarding the

\footnotetext{
${ }^{1}$ Eva Živčicová, Alexander Dubček University of Trenčín, Slovakia, eva.zivcicova@tnuni.sk

${ }^{2}$ Monika Gullerová, Faculty of Social and Economic Relations, Alexander Dubček University of Trenčín, Slovakia, monika.gullerova@tnuni.sk
} 
term quality of life, Pacione (2003, p. 20) notes that "quality is not an attribute inherent in the environment, but it is a behavior-related function of an interaction of environmental characteristics and person characteristics." When quality of life involves interactions, not only objective factors but also subjective perceptions are to be taken into consideration. In order to research quality of life, it is essential to identify objective components to serve as the baseline. Next, from the psychological point of view, it is crucial to define components of the subjective perception, such as selection, assessment, and emotional well-being. Since there are various definitions as to what is meant by quality of life, there are also various indicators applied to measure quality of life. In order to measure quality of life, both external and internal indicators are used. In this article, we focus on the subjective assessment of several domains of quality of life by respondents with and without diabetes mellitus.

\section{Methods}

This quantitative study into self-perceived quality of life is to compare selected QoL domains in respondents with and without diabetes mellitus. The sample contained 50 respondents, and a sampling quota with regard to sex and health status was applied. The World Health Organization Quality of Life Assessment (WHOQOL-BREF) was used to conduct the empirical research. The WHOQOL-BREF allows a quality of life assessment that is applicable cross-culturally. The WHOQOL-BREF contains 24 questions under four domains, including physical health, psychological, social relationships, and environment. In addition, there are two items that are examined separately: question 1 asks about an individual's overall perception of quality of life, and question 2 asks about an individual's overall perception of their health. Respondents assess quality of life on a 5-point categorical rating scale. Domain scores are scaled in a positive direction. The mean score of items within each domain is used to calculate the domain score. Domain scores are raw scores that are converted to transformed scores. The first transformation method converts scores in a range from 4-20, comparable with WHOQOL100. The second transformation method converts domain scores to a $0-100$ scale. The transformed score is comparable to other questionnaires measuring quality of life. The advantage of the questionnaire is that the scores for each domain can be compared as population values are given. The questionnaire was tested in 23 countries, including Slovakia. Results obtained from the questionnaire of the World Health Organization, WHOQOL-BREF, can be analyzed and interpreted in four domains and two additional questions about an individual's overall perception of quality of life and health. Table 1 lists the data in absolute values obtained from respondents both with and without diabetes mellitus.

Table 1: Assessment of questionnaire domains

\begin{tabular}{|l|c|c|c|c|}
\hline & $\begin{array}{c}\text { Respondents without } \\
\text { diabetes }\end{array}$ & $\begin{array}{c}\text { P } \\
\text { value * }\end{array}$ & $\begin{array}{c}\text { SD* } \\
*\end{array}$ & $\begin{array}{c}\text { Respondents with } \\
\text { diabetes }\end{array}$ \\
\hline Domain 1 - physical health & 17.14 & 15.55 & 2.55 & 9.94 \\
\hline Domain 2 - psychological & 16.52 & 14.78 & 2.43 & 9.8 \\
\hline Domain 3 - social relationships & 15.7 & 14.98 & 2.89 & 10.14 \\
\hline Domain 4 - environment & 15 & 13.3 & 2.08 & 10.72 \\
\hline $\begin{array}{l}\text { Question 1 - Self-perception of } \\
\text { quality of life }\end{array}$ & 4.06 & 3.82 & 0.72 & 2.12 \\
\hline $\begin{array}{l}\text { Question 2 Self-perception of } \\
\text { health }\end{array}$ & 4.06 & 3.68 & 0.85 & 2.04 \\
\hline
\end{tabular}

* p values for the Slovak population according to Dragomerická, Bartoňová, 2006, p.42)

**standard deviation

Source: Authors 


\section{Results and discussions}

We calculated and analyzed the data obtained from respondents. Based on population values and their respective standard deviation, we made a list of the values obtained from respondents with and without diabetes mellitus.

\begin{tabular}{|c|r|r|l|}
\hline Table 2: Quality of life assessment—respondents without diabetes mellitus \\
\hline Questionnaire items & $\begin{array}{c}\text { Respondents without } \\
\text { diabetes }\end{array}$ & Variance in p value & \multicolumn{1}{|c|}{$\begin{array}{c}\text { Quality of life } \\
\text { assessment }\end{array}$} \\
\hline Domain 1 & 17.14 & +1.54 & slightly increased \\
\hline Domain 2 & 16.52 & +1.72 & slightly increased \\
\hline Domain 3 & 15.70 & +0.70 & average \\
\hline Domain 4 & 15.00 & +1.70 & slightly increased \\
\hline Question 1 & 4.06 & +0.24 & average \\
\hline Question 2 & 4.06 & +0.38 & average \\
\hline
\end{tabular}

Source: Authors

\begin{tabular}{|c|r|r|l|}
\hline \multicolumn{2}{|c|}{ Table 3: Quality of life assessment—respondents with diabetes mellitus } \\
\hline Questionnaire items & $\begin{array}{c}\text { Respondents with } \\
\text { disease }\end{array}$ & Variance in p value & Quality of life assessment \\
\hline Domain 1 & 9.94 & -5.66 & highly decreased \\
\hline Domain 2 & 9.80 & -5.00 & highly decreased \\
\hline Domain 3 & 10.14 & -4.86 & decreased \\
\hline Domain 4 & 10.72 & -2.58 & decreased \\
\hline Question 1 & 2.12 & -1.70 & below average \\
\hline Question 2 & 2.04 & -1.64 & decreased \\
\hline
\end{tabular}

Source: Authors

The results indicate that respondents with diabetes mellitus assess their overall subjective quality of life below average, and respondents without diabetes mellitus average. We assumed that health satisfaction will be lower in the group of respondents with the disease, which is revealed by the reduced variance in $\mathrm{p}$ value (-1.64).

\begin{tabular}{|c|c|c|c|c|c|c|c|}
\hline$\stackrel{\mathscr{E}}{\Xi}$ & 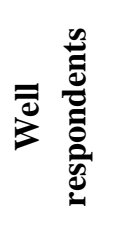 & 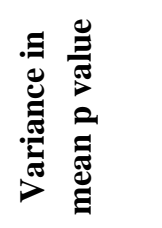 & $\begin{array}{l}\text { Quality of life } \\
\text { assessment }\end{array}$ & 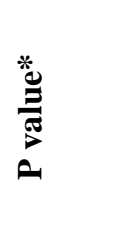 & 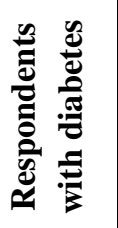 & 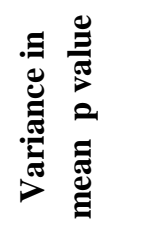 & $\begin{array}{l}\text { Quality of life } \\
\text { assessment }\end{array}$ \\
\hline D1 & 17.14 & +1.54 & slightly increased & 15.55 & 9.94 & -5.66 & highly decreased \\
\hline D2 & 16.52 & +1.72 & slightly increased & 14.78 & 9.80 & -5.00 & highly decreased \\
\hline D3 & 15.70 & +0.70 & average & 14.98 & 10.14 & -4.86 & decreased \\
\hline
\end{tabular}


CBU INTERNATIONAL CONFERENCE ON INNOVATION, TECHNOLOGY TRANSFER AND EDUCATION

\begin{tabular}{|l|r|r|l|r|r|r|l|}
\hline D4 & 15.00 & +1.70 & slightly increased & 13.3 & 10.72 & -2.58 & decreased \\
\hline Q1 & 4.06 & +0.24 & average & 3.82 & 2.12 & -1.70 & below average \\
\hline Q2 & 4.06 & +0.38 & average & 3.68 & 2.04 & -1.64 & decreased \\
\hline
\end{tabular}

Source: Authors

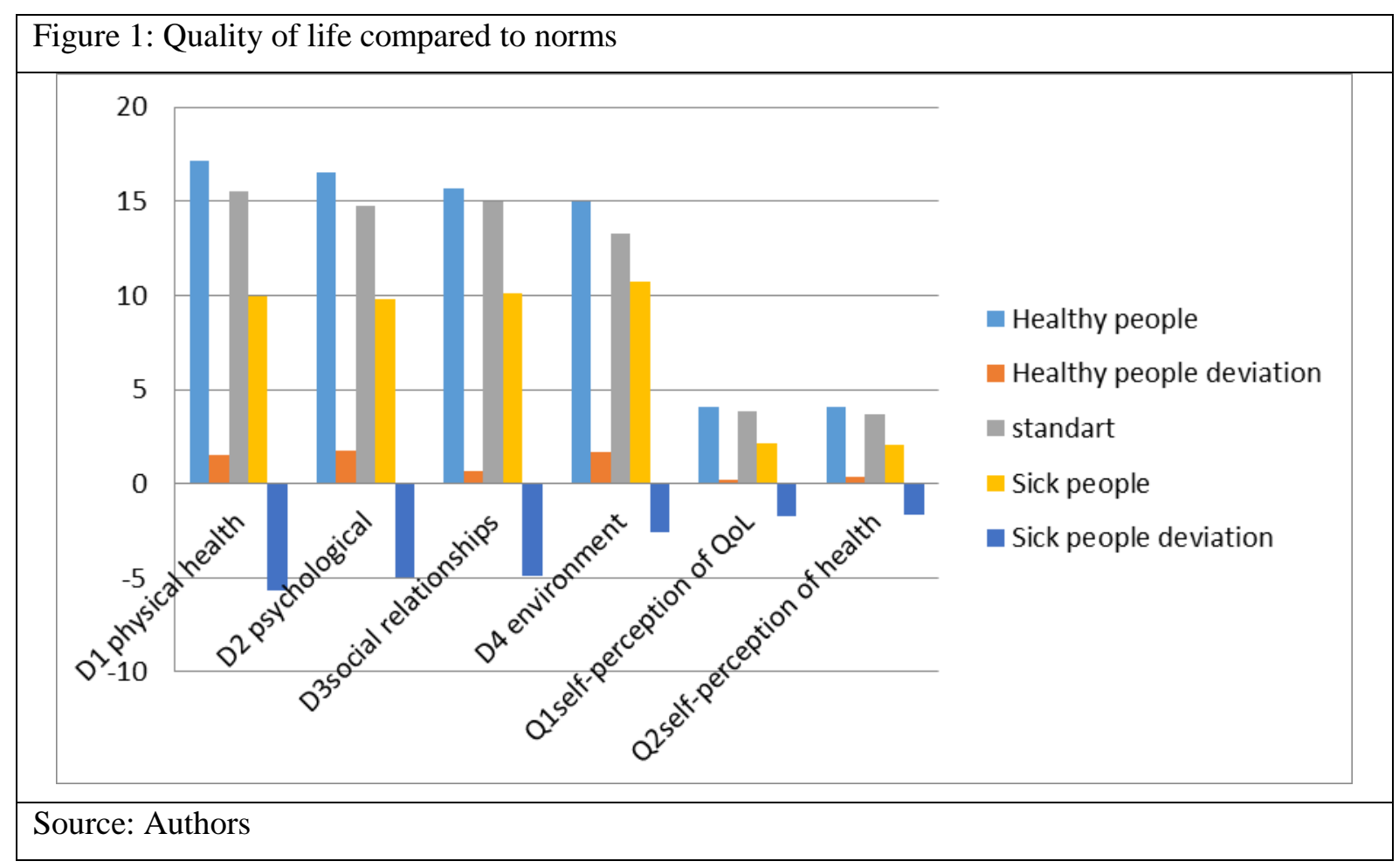

\section{Conclusion}

Several studies have addressed the issue of life quality of patients with diabetes. Some authors (Brähler, Schumacher, \& Strauss, 2003; Stewart et al., 1989) maintain that the most significant factors affecting changes in life quality over a three-year period do not include taking or not taking hormone medicine, but rather include older age, hypertension, angina pectoris, and heart failure. The empirical study revealed reduced satisfaction with health among respondents with diabetes and the lowest scores were found in the domain of physical health. It is worth mentioning that reduced quality of life was found even in the environment domain. Both domains mentioned are distinctly assessed by both groups of respondents. Other longitudinal empirical studies reveal that the long-term subjective assessment of the quality of life of patients with diabetes is comparable to other chronically-ill patients. We agree with Ryan (1997) that life quality should be assessed in line with the parameters that affect the physical and mental health, and directly affecting mental and social functioning of an individual. Since the chronically-ill cannot be healed completely, humanization of care for patients with long-term conditions, while placing emphasis on quality of life, is of utmost importance. 


\section{References}

Brähler, E., Schumacher, J., \& Strauss, B. (Eds.) (2003). Diagnostische Verfahren in der Psychotherapie [Diagnostic methods in psychotherapy]. Gottingen: Hogrefe.

Dragomerická, E., \& Bartoňová, J. (2006). WHOQOL-BREF, WHOQOL-100. Users Guide to the Czech version of the quality of life of the World Health Organization. Prague: Prague Psychiatric Center.

Hancock, T. (2000). Quality of life indicators and the DHC. South-eastern Ontario.

Kováč, D. (2006). Kultiváciou osobnosti k excelentnej kvalite života [The cultivation of personalities and excellent quality of life]. In I. Ruisel et al., Úvahy o inteligencii a osobnosti [Reflections on intelligence and personality] (pp. 11-38). Bratislava: Slovak Academic Press.

Lane, J. E. (1996). Constitutions and political theory. Manchester Univ. Press: Manchester.

Pacione, M. (2003). Urban environmental quality and human wellbeing-a social geographical perspective. Landscape and Urban Planning, 65, 19-30.

Rapley, M. (2003). Quality of Life Research: A Critical Introduction. Sage Publications: London.

Ryan, C. M. (1997). Psychological factors and diabetes mellitus. In: J. Pickup, \& G. Williams, Textbook of diabetes (pp. 66.1-66.16). Oxford: Blackwell.

Stewart, A. L., Greenfield, S., Hays, R. D., Wells, K., Rogers, W. H., Berry, S. D., McGlynn, E. A., \& Ware, J. E. (1989). Functional Status and Well-being of Patients with Chronic Conditions: Results from the Medical Outcomes Study. JAMA Internal Medicine, 262, 907-913.

The Whoqol-Group (1998). The development of the World Health Organization quality of life assessment instrument: The WHOQOL. In: J. Orley, \& W. Kuyen (Eds.), Quality of life assessment: International perspectives. Berlin: Springer.

Tokárová, A. (2002). Sociálna práca. Kapitoly z dejín, teórie a metodiky sociálnej práce [Social Work: The History, Theory and Methodology of Social Work]. Faculty of Arts, University of Prešov. 